\title{
2A: $H$. pylori infection leading to cancer
}

\section{A:01 REMISSION OF PRIMARY GASTRIC MALT LYMPHOMA AFTER CURE OF HELICOBACTER PYLORI INFECTION: A TWO-YEAR FOLLOW-UP REPORT OF THE GERMAN MALT LYMPHOMA TRIAL}

E. Bayerdörffer, A. Morgner, A. Neubauer, B. Rudolph, C. Thiede, N. Lehn, E. Seifert, M. Frevel, A. Sommer, H. Schulz, H. Heidt, B. Geiter, P. Rohde, H. Klann, M. Stolte. Dept. of Gastroenterology, Univ. of Magdeburg; Dept. of Hematology \& Oncology, Humboldt-Univ. of Berlin; Institute for Pathology, Klinikum Bayreuth; MALT lymphoma group

Background: Primary gastric low-grade lymphoma of the mucosa associated lymphoid tissue type has been suggested to arise from chronic $H$. pylori gastritis. These lymphomas may regress completely in about $70 \%$, when $H$. pylori infection is cured. We report on a 2 year median follow-up period of 50 patients with MALT lymphoma after cure of $H$. pylori infection.

Methods: 50 patients with consecutive primary gastric MALT lymphoma and $H$. pylori infection were treated with omeprazole $40 \mathrm{mg}$ tid and amoxicillin $750 \mathrm{mg}$ tid for 14 days to cure the infection. In addition to histology, PCR was used to study proliferation of monoclonal B-cells.

Results: 50 patients became $H$. pylori negative, 2 after a second treatment course. $80 \%$ (40 out of 50 ) showed complete histological remission of their lymphoma after a median time period of 5.5 months, and 3 out of $50(6 \%)$ so far showed partial remission. 6 patients $(12 \%)$ did not respond to cure of $H$. pylori infection, and underwent surgical treatment. Of those 6 treated surgically, 4 were found to have a high-grade lymphoma, and 1 patient was found to have a high-grade T-cell lymphoma. 1 patient $(2 \%)$ was primarily treated by chemotherapy (CHOP). PCR showed complete regression of monoclonal bands in most cases. During a median follow-up time period of 24 months, only one relapse of gastric B-cell MALT lymphoma was observed in one patient after 13 months of successful treatment. However 1 patient developed a high-grade B-cell lymphoma of the nasal concha.

Conclusion: These data suggest, that low-grade B-cell MALT lymphoma may regress in more than $70 \%$ after cure of $\boldsymbol{H}$. pylori infection. Further, remission is stable for at least 2 years in most patients.

\section{A:02 REGRESSION OF PRIMARY GASTRIC LOW-GRADE MALT LYMPHOMA AFTER CURE OF HELICOBACTER PYLORI INFECTION - GERMAN MALT LYMPHOMA TRIAL}

A. Morgner, E. Bayerdörffer, A. Neubauer, B. Rudolph, C. Thiede, N. Lehn, E. Seifert, M. Frevel, A. Sommer, H. Schulz, H. Heidt, B. Geiter, P. Rohde, H. Klann, M. Stolte. Dept. of Gastroenterology, Univ. of Magdeburg, Germany; Dept. of Hematology \& Oncology, Humboldt-Univ. of Berlin, Germany; Institute for Pathology, Klinikum Bayreuth, Germany; MALT lymphoma study group, Germany

Background: Primary gastric low-grade lymphoma of the mucosa associated lymphoid tissue type (MALT) has been suggested to arise from chronic $H$. pylori gastritis.

Methods: 83 patients with histologically confirmed, primary gastric lowgrade MALT lymphoma in clinical stage $\mathrm{EI}_{1}$ who were infected with $H$. pylori were treated with omeprazole $40 \mathrm{mg}$ tid combined with amoxicillin $750 \mathrm{mg}$ tid for 14 days to cure the infection. In addition to histology PCR was used to study proliferation of monoclonal B-cells at each monthly endoscopic examination.

Results: All patients had at least 2 post-treatment endoscopic examinations, and all became negative for $H$. pylori, 4 after a second treatment course. On histology, $66(80 \%)$ patients showed complete remission after a median time period of 6 months, and $6(7 \%)$ showed partial remission of lymphoma after 12.5 months. Eleven patients (13\%) revealed no change of their tumour within a median time period of 4.5 months after cure of $H$. pylori infection. Eight of them were treated surgically and 3 by chemotherapy. Of those 8 treated surgically, and of those 3 treated by chemotherapy, 6 were found to have high-grade lymphoma on histology. PCR showed complete disappearance of monoclonal B-cells, in 3 patients 4 months later than the histological disappearance of the lymphomas. During a median follow-up period of 14 months, only one relapse of MALT lymphoma was detected in one patient 13 months after successful treatment.

Conclusion: Low-grade primary gastric MALT lymphoma may completely regress after cure of $H$. pylori infection. However, longer follow-up is needed to clarify whether the remission is lasting.

\section{A:03 COMPLETE REMISSION OF HELICOBACTER} HEILMANNII-ASSOCIATED PRIMARY GASTRIC LOW-GRADE MALT LYMPHOMA AFTER CURE OF THE INFECTION

A. Morgner, N. Lehn, B. Rudolph, C. Thiede, A. Meining, E. Seifert, S. Müller, A. Neubauer, M. Stolte, E. Bayerdörffer. Dept. of Gastroenterology, Univ. of Magdeburg; Dept. of Hematology \& Oncology, Humboldt-Univ. of Berlin; Institute for Pathology, Klinikum Bayreuth

Background: Primary gastric low-grade MALT lymphoma has been suggested to arise from chronic $H$. pylori gastritis. Cure of the infection leads to complete remission of stage I lymphomas in about $70 \%$ of the cases. The aim of this study was to investigate whether $H$. heilmanni infection-associated primary gastric MALT lymphoma will regress after cure of the infection, too.

Methods: Three consecutive patients with $H$. heilmannii gastritis coincident with a primary gastric MALT lymphoma in clinical stage I were treated with $40 \mathrm{mg}$ omeprazole tid combined with $750 \mathrm{mg}$ amoxicillin tid for 14 days to cure the infection. In addition to histological evaluation, PCR was used to study proliferation of monoclonal B-cells before treatment and during follow-up.

Results: Treatment resulted in the cure of $H$. heilmannii infection in each case, and complete histological, endoscopic and molecular remission of the tumours within a median post treatment period of one months (range 1-7 months) Over a median follow-up period of 7 months, no relapse of lymphoma or reinfection with $H$. heilmannii occurred

Conclusion: These data suggest that gastric MALT lymphoma may arise not only in patients with chronic $H$. pylori-associated gastritis, but also in those with gastritis associated with $H$. heilmannii. Cure of the infection may lead to complete remission of the MALT lymphoma.

\section{A:04 GASTRIC CARCINOMA RISK INDEX IN PATIENTS INFECTED WITH HELICOBACTER PYLORI}

A. Meining, M. Stolte, P. Müller, N. Lehn, D. Hölzel, E. Bayerdörffer. Dept. of Internal Med. II \& Epidemiology, Univ. of Munich; Dept. of Pathology, Klinikum Bayreuth, Germany

Background: Epidemiological data have suggested an association between chronic $H$. pylori gastritis and gastric carcinoma. However, the majority of the infected persons will not develop gastric cancer.

Aim: To investigate the histological features of $H$. pylori infected patients having early-stage gastric carcinoma (EGC) in comparison with duodenal ulcer (DU) patients, who are known to have a low risk for developing EGC.

Methods: 2 antral and 2 corpus biopsy specimens of 117 EGC-patients and of 117 age-matched DU-patients were examined histologically according to the Sydney System.

Results: Infiltration with lymphocytes/plasma cells in the corpus was greater or equal to that in the antrum in $53.8 \%$ of the patients with EGC and in $12.8 \%$ of the patients with DU (chi-square: $p<0.001$ ). Neutrophil infiltration in the corpus was more pronounced or equal to that in the antrum in $55.5 \%$ of the EGC-patients and in $13.7 \%$ of the DU-patients $(\mathrm{p}<0.001) .68 .4 \%$ of the EGC-patients and $28.2 \%$ in the DU-group had intestinal metaplasia $(p<0.001)$. Based on these significant differences, we suggest a gastric cancer risk index:

Lymphocytes/plasma cell infiltr.: Infiltration with neutrophils:
Presence of intestinal metaplasia:

corpus $\geq$ antrum: $\quad 1$ POINT

\section{corpus $\geq$ antrum: $\quad 1$ POINT}

1 POINT

Calculated on the basis of our study population, predictive values $(\log$. regression) for having EGC are as following:

\begin{tabular}{llll}
\hline & EGC $(\mathrm{n})$ & DU $(\mathrm{n})$ & Predictive value \\
\hline 0 points: & 12 & 68 & 0.166 \\
1 point: & 37 & 35 & 0.464 \\
2 points: & 33 & 13 & 0.791 \\
3 points: & 35 & 1 & 0.943 \\
\hline
\end{tabular}

Conclusion: This uncomplicated index might be useful to identify those patients infected with $H$. pylori who might have an increased risk for developing gastric cancer and may thus benefit from preventive anti- $H$. pylori treatment. 
2A:05 LOW-GRADE MALTOMA OF THE STOMACH: RUSSIAN EXPERIENCE

V.A. Isakov, L.E. Gurevitch. Moscow Regional Research Clinical Institute (MONIKI), Moscow, Russia

During the last two years we have followed-up 5 women and 1 man with low-grade MALTomas of the stomach. The mean age was 51.8 years. The diagnosis was confirmed by histology and monoclonality of tumor cells was confirmed by immunohistochemistry with $\kappa$ and $\lambda$ light chains antibodies. All patients received triple therapy that consisted of CBS (Denol) $120 \mathrm{mg}$ qid, ampicillin $500 \mathrm{mg}$ qid and methronidazole $250 \mathrm{mg}$ qid during 14 days. $\mathrm{H}$. pylori was eradicated in 5 patients. In all these patients the regression of MALToma was progressively noted. It started with the decrease of density of infiltrate in lamina propria of gastric mucosa, then lympho-epithelial lesions disappeared. Nevertheless, at that period of time and up to the 8 month after treatment monoclonality of cells infiltrating lamina propria was revealed by immunohistochemistry with anti- $\kappa$-antibodies in two patients. Nine months after the cessation of the therapy the biological remission of low grade MALToma was achieved in all 5 patients in whom the $\mathrm{H}$. pylori was successfully eradicated. During the follow-up period one patient relapsed after 8 months of biological remission with $\mathrm{H}$. pylori reinfection and showed reappearance of all features of low-grade MALToma including lympho-epithelial lesions and mucosal ulceration. After the repetition of the triple therapy $\mathrm{H}$. pylori was eradicated again and after 6 mo biological remission of MALToma was achieved. In conclusion: Eradication of H. pylori leads to histological and later on to biological remission of low-grade MALToma of the stomach. Reinfection of $\mathbf{H}$. pylori followed by rapid relapse of MALToma.

\section{A:06 ANTIBODIES IN GASTRIC CANCER PATIENTS TO THE CYTOTOXIN ASSOCIATED ANTIGENE, Cag A}

M. Held ${ }^{1,2}$, O. Nyrén ${ }^{1}$, L.E. Hansson ${ }^{1}$, T. Wadström ${ }^{2}$, H.O. Adami ${ }^{1}$, L. Engstrand ${ }^{1}$. 1 Dep. of Cancerepidemiology, Uppsala, Sweden; ${ }^{2}$ Dep. of Medical Microbiology, Lund, Sweden

The connection between Helicobacter pylori infection and gastric cancer is becoming well established, but it is uncertain whether all strains possess a carcinogenic potential. We tested the hypothesis that strains expressing the $120 \mathrm{kDa}$ product of the cytotoxin associated gene, cagA, are more closely linked to gastric carcinogenesis than other strains.

In a hospital-based case-control study, we collected sera from 125 consecutive patients, with a newly diagnosed gastric adenocarcinoma, and 107 controls. The presence of antibodies to $H$. pylori was analysed by an IgG enzyme-linked immunosorbent assay (HM-CAP), and antibodies to the $120 \mathrm{kDa}$ antigen were detected by immunoblot. Unconditional logistic regression was used to obtain age- and sex-adjusted odds ratios (ORs) as estimates of relative risk.

Overall case-control analysis by HM-CAP revealed an almost 3-fold increased risk of gastric cancer in seropositive patients relative to seronegative (adjusted $\mathrm{OR}=2.6 ; 95 \% \mathrm{CI} 1.4-4.8$ ). The presence of antibodiès to the $120 \mathrm{kDa}$ antigen was more strongly associated with the risk of gastric cancer $(O R=4.0 ; 95 \%$ CI 2.1-7.5) and even more when confining the analysis to non-cardia gastric cancer $(O R=6.1 ; 95 \%$ CI 2.8-13.0). Analysis of cases and controls who were $H$. pylori infected, according to HM-CAP, showed a five times higher risk of non-cardia gastric cancer for persons expressing antibodies to CagA compared to those infected with CagA-negative strains.

Our data support the hypothesis that patients infected with cagA expressing $H$. pylori strains run a greater risk of developing gastric cancer than patients infected with strains which do not express cagA.

\section{A:07 AN INTERNATIONAL ASSOCIATION BETWEEN PREVALENCE OF INFECTION WITH CagA POSITIVE STRAINS OF H. PYLORI AND MORTALITY FROM GASTRIC CANCER}

P.M. Webb ${ }^{1}$, D. Forman, D. Newell ${ }^{2}$, A. Covacci ${ }^{3}$, J.E. Crabtree and the Eurogast Study Group. University of Leeds \& St. James's Hospital, Leeds, UK; ${ }^{1}$ University of Queensland, Brisbane, Australia; ${ }^{2}$ Central Vet Labs, Weybridge, UK; ${ }^{3}$ IRIS, Siena, Italy

Purpose: There has been considerable recent interest in whether individuals infected with strains of $H$. pylori, expressing the cagA gene product, have an increased risk of gastric cancer in comparison with those infected with cagA negative strains. This question has been investigated in the Eurogast study in which we have previously demonstrated an international correlation between gastric cancer mortality rates and $H$. pylori infection prevalence.
Methods: A total of 2839 serum samples, collected in 1990-2 from approximately 50 men and 50 women in the age groups 25-34 and 55-64 years from each of the 17 Eurogast study centres, were analysed in a single laboratory for the presence of IgG antibodies to the CagA protein by an ELISA using as antigen a purified recombinant fragment of CagA. Regression analyses were then carried out in which the prevalence of CagA seropositivity was modelled on the cumulative (0-74 yrs) gastric cancer mortality rate for each population in the mid-1980's.

Results: There was a statistically significant association $(p=0.01)$ between the prevalence of individuals with CagA seropositivity in each population and the mortality rate from gastric cancer. The regression coefficient (2.76) was higher than that for the effect of $H$. pylori seropositivity (1.72) although the latter was of similar significance $(p=0.002)$. Based on these data, the relative risk of gastric cancer associated with CagA positive $H$. pylori infection would be 15.8 in comparison with a risk of 5.6 associated with $H$. pylori per se.

Conclusions: These results provide evidence to suggest that the worldwide variation in gastric cancer mortality may be associated more strongly with the variation in infection with CagA positive strains than with CagA negative strains of $H$. pylori.

\section{A:08 ONGOING SOMATIC HYPERMUTATIONS AND CLONAL EVOLUTION IN GASTRIC B-CELL LYMPHOMAS OF THE MUCOSA ASSOCIATED LYMPHOID TISSUE (MALT) AFTER} ERADICATION OF H. PYLORI (HP)

C. Thiede, B. Alpen, E. Bayerdörffer, B. Rudolph, A. Morgner, M. Stolte, A. Neubauer. Virchow Klinikum, Humboldt University, Berlin, Germany

Primary gastric B-cell MALT-lymphoma has been linked to chronic infection with $\mathrm{Hp}$, eradication of which leads to remission of the lymphomas in the majority of the patients. Here we report on molecular analysis of five cases of primary gastric MALT-lymphoma. After eradication of $\mathrm{Hp}$, all patients became Hp negative; three of five patients showed clinical and histological CR; two patients did not respond, one of which was referred to gastrectomy. Despite this different clinical behaviour, all patients were persistently monoclonal in $\mathrm{PCR}$ performed on the rearranged immunoglobulin heavy chain variable region using generic FR1, FR2 and FR3-region and $\mathrm{JH}$ primers. Since clinically, MALT-lymphomas seem to be antigen responsive, we asked, whether Hp-eradication has an effect on these B-cell populations. Monoclonal PCR-products were subcloned and 7-20 clones carrying inserts were sequenced for the initial sample and for three to five follow-up biopsies. The $\mathrm{V}_{\mathrm{H}}$-sequences found displayed several somatic mutations with predominance of replacement mutations in the antigencontacting complementarity determinating regions (CDRs). In addition, all but one of the corresponding $\mathrm{V}_{\mathrm{H}}$-germline sequences had previously been isolated from autoreactive antibodies. In four of five patients, eradication of $\mathrm{Hp}$ was followed by induction of clonal subpopulation present at diagnosis or even induced the appearance of new clones with additional mutations. These results support the notion, that gastric MALT-lymphomas are likely to be antigen responsive. The fact that antigen selection seems to be present after Hp-eradication suggests that other antigens, presumably autoantigenic structures, are important. The implications of these findings for the treatment of MALT-lymphoma patients remain to be determined.

\section{A:09 FREQUENT USAGE OF SPECIFIC IMMUNOGLOBULIN HEAVY CHAIN VARIABLE REGION $\left(V_{H}\right)$ GENES IN LYMPHOMAS OF THE MUCOSA-ASSOCIATED LYMPHOID TISSUE (MALT)}

C. Thiede, B. Alpen, E. Bayerdörffer, B. Rudolph, A. Morgner, M. Stolte, A. Neubauer. Virchow Klinikum, Humboldt University, Berlin, Germany

Background: Low-grade gastric B-cell lymphomas of MALT are very frequently associated with chronic $H$. pylori $(\mathrm{Hp})$ infection. The fact that eradication of $\mathrm{Hp}$ induces regression of the lymphoma in the majority of the patients together with the presence of Hp-specific T-cells supports the notion, that these lymphomas are Hp-responsive. On the other hand, recent work suggests that autoreactivity may also be important in the development of the lymphomas. Other autoreactive diseases like systemic lupus erythematosus or rheumatoid arthritis are often associated with autoantibodies encoded by specific germline $\mathrm{V}_{\mathrm{H}}$-genes. Aim: To analyze $\mathrm{V}_{\mathrm{H}}$-gene usage and the pattern of somatic mutations in 14 patients with primary gastric MALT lymphoma. Methods: PCR on $\mathrm{V}_{\mathrm{H}} \mathrm{DJ}_{\mathrm{H}}$ rearrangements was performed using genomic DNA and generic primers for the framework and joining region. Monoclonal PCR-products were cloned and sequenced. Results: $\mathrm{V}_{\mathrm{H}}$-sequences found were homologous to $\mathrm{V}_{\mathrm{H}} 1$-family genes in $21 \%$ and to $\mathrm{V}_{\mathrm{H}} 3$ and $\mathrm{V}_{\mathrm{H}} 4$-family genes in $57 \%$ and $21 \%$ respectively. All three $V_{H} 1$-sequences were derived from the same germline gene (DP10) and three of the eight $\mathrm{V}_{\mathrm{H}}$ 3-sequences used the DP54 alelle. Somatic mutations were found in all sequences, with higher incidence of replacement mutations in the antigen contacting complementarity determinating regions 
(CDRs). Twelve of $14 \mathrm{~V}_{\mathrm{H}}$-germline genes had previously been isolated from various autoreactive antibodies. Conclusion: These findings support the notion that MALT lymphomas develop from B-cells that have been exposed to antigen, most likely post germinal center B-cells. The high incidence of $\mathrm{V}_{\mathrm{H}}$-alleles associated with autoreactivity and preference of specific germline $\mathrm{V}_{\mathrm{H}}$-genes points to fact that autoreactivity may be an important driver of the disease.

\section{A:10 CYTOTOXIN ACTIVITY AND VaCA SUBTYPES IN H. PYLORI ASSOCIATED WITH MALT LYMPHOMA OR SIMPLE GASTRITIS}

S. Miehlke, N. Lehn, K. Schweiger, E. Bayerdörffer, D.Y. Graham, M.F. Go. VAMC, Houston, TX, USA; Univ. of Magdeburg, Germany; MALT Lymphoma Study Group, Germany

Background: $H p$ infection is strongly linked to primary gastric MALTlymphoma. Most, if not all $\mathrm{Hp}$ have the vacA gene but only a subset express the cytotoxin. It has been suggested that the vacA s1 subtype is associated with cytotoxin activity.

Methods: We determined the activity of the vacuolating cytotoxin and the frequency of vacA signal- and midregion sequences (s1, s2; $\mathrm{m} 1$, m2) in $H p$ isolates obtained from 39 patients (16 with low-grade gastric MALT-lymphoma and 23 with simple $H p$ gastritis). Cytotoxin activity was examined in HeLa and Vero cells, and was defined as more than $50 \%$ vacuolation of cells. Presence of vacA signal-and midregion sequences was determined by PCR.

Results:

\begin{tabular}{llllll}
\hline & MALT (n=16) & & \multicolumn{2}{l}{ Gastritis (n = 23) } \\
\cline { 2 - 3 } \cline { 5 - 6 } & tox+ (HeLa) & tox+(Vero) & & tox+(HeLa) & tox+ (Vero) \\
\hline S1/M1 & $3 / 5(60 \%)$ & $2 / 5(40 \%)$ & & $3 / 6(50 \%)$ & $3 / 6(50 \%)$ \\
S1/M2 & $0 / 7(0 \%)$ & $1 / 7(14 \%)$ & & $1 / 12(8 \%)$ & $7 / 12(58 \%)$ \\
S2/M2 & $0 / 4(0 \%)$ & $0 / 4(0 \%)$ & $0 / 5(5 \%)$ & $0 / 5(0 \%)$ \\
\hline
\end{tabular}

The $\mathrm{s} 1 / \mathrm{ml}$ genotype was found in $28 \%(11 / 39)$ of all strains studied Cytotoxin activity was identified in $63 \%(7 / 11)$ of strains with the $\mathrm{s} 1 / \mathrm{m} 1$ type. Using HeLa cells cytotoxin activity was found in 55\% (6/11) of $H p$ $\mathrm{s} 1 / \mathrm{m} 1$ genotype but in only $5 \%(1 / 19)$ of the $s 1 / \mathrm{m} 2$ genotype. In Vero cells cytotoxic activity was found in $42 \%(8 / 19)$ of $\mathrm{s} 1 / \mathrm{m} 2$ genotype. No strain with $v a c A$ genotype $s / \mathrm{m} 1$ was identified $(\mathrm{p}<0.001)$.

Conclusions: Vacuolization of Vero cells was observed with both $\mathrm{s} / \mathrm{ml}$ and $s 1 / \mathrm{m} 2$ vacA types, but only in the $s 1 / \mathrm{m} 1$ genotype using HeLa cells. There was no difference in vacA genotypes or pattern of cytotoxic activity between $H p$ from gastritis or low grade MALT-lymphoma. These data suggest that use of a single cell line may underestimate the frequency of cytotoxin activity.

\section{A:11 GASTRIC CANCER IN KOREA HAS A DIFFERENT CagA PHENOTYPE THAN DUODENAL ULCER OR SIMPLE $H$. PYLORI GASTRITIS}

S. Miehlke, M.F. Go, J.G. Kim, D.Y. Graham, N. Figura. VAMC, Houston, TX, USA; University of Siena, Italy; Guro Hospital, Korea University College of Medicine, Seoul, Korea

Background: Infection with cagA-positive $H p$ strains is frequent in Korea While DU and gastric carcinoma are mutually exclusive, it is not known if this is secondary to disease-specific $H p$ strains or host factors. We asked if there were phenotypic differences in the CagA protein of $\mathrm{Hp}$ from patients with gastric carcinoma, DU or simple $H p$ gastritis. Methods: $H p$ was isolated from gastric biopsies from 75 patients from Korea (25 with gastric cancer, 25 with DU, and 25 simple $H p$ gastritis). CagA expression in $H p$ isolates was determined by Western blotting on coded samples of bacterial suspensions. Presence of the cagA gene was determined by PCR. Results: All $H p$ isolates expressed the CagA protein with molecular weights (MW) ranging from 115 to $150 \mathrm{k}$ (mean $134.5 \mathrm{k}$ ). The $\mathrm{MW}$ of CagA form gastric cancer patients was significantly greater than those with DU or simple $H p$ gastritis ( $135.5 \mathrm{k}, 131.2 \mathrm{k}$, and $131 \mathrm{k}$, respectively) $(\mathrm{p}<0.01)$. Incidentally, the intensity of CagA molecular weight bands appeared to be greater in strains from patients with gastric carcinoma or duodenal ulcer compared to those from patients with simple gastritis. Conclusions: While there is no disease related difference in the prevalence of cagA among $H p$ isolated from Korean patients, there are marked phenotypic differences reflected by a high MW CagA protein in gastric carcinoma. High MW CagA may be involved in pathogenesis or may simply be a marker for $\mathrm{Hp}$ strains with a predilection to cause gastric cancer or the precursor lesion, multifocal gastritis with atrophy.

\section{A:12 GASTRIC CARCINOMA (GC) AND H. PYLORI: A CASE-CONTROL STUDY IN BRAZIL}

D.M.M. Queiroz, G.A. Rocha, E.N. Mendes, C.A. Oliveira. MMDA Cabral. Lab. of Research in Bacteriology/UFMG, B. Horizonte, Brazil

$H$. pylori (HP) infection diagnosis by culture, urease test and histopathological examination is difficult in patients with GC because they present atrophy, intestinal metaplasia and high $\mathrm{pH}$ which result in reduced colonization by HP. In addition, the serum levels of IgG to HP seem also to be lower in GC patients. Therefore, there is not agreement among the results of case-control studies when the material is obtained after the diagnosis, specially in developing countries where the prevalence of the infection in general population is very high. In this study, four methods were used for $\mathrm{HP}$ infection diagnosis in patients with GC and controls. Fifty patients with distal GC (37 male, 13 female, mean age $63.5 \mathrm{yr}$, range 32-96) and 100 patients without gastric cancer (29 with duodenal ulcer) who underwent upper gastrointestinal endoscopy for evaluation of gastric symptoms were studied. Each case patient was matched with two control patients according to age, sex, social class and region of $M$. Gerais state, Brazil. Specimens from the antral and oxyntic mucosa were obtained from all patients (from gastric cancer patients, $n=40$ at surgery and $n=10$ at endoscopy) for culture onto BHM, urease test and stained smears. Sera collected from all patients were tested for antibodies to HP by using a highy sensitive and specific IgG enzyme-linked immunosorbent assay (Cobas Core anti-HP EIA, Roche). HP infection was detected in 49 (98\%) gastric cancer patients and in $79(79 \%)$ control patients. The sensitivity of the methods is shown below.

\begin{tabular}{|c|c|c|c|c|c|}
\hline & \multicolumn{2}{|c|}{ Cancer $(n=50)$} & \multicolumn{2}{|c|}{ Control $(n=100)$} & \multirow{2}{*}{$\begin{array}{l}\text { Sensitivity } \\
\%\end{array}$} \\
\hline & $\overline{\mathrm{N}}$ & $\%$ & $\overline{\mathrm{N}}$ & $\%$ & \\
\hline $\begin{array}{l}\text { Culture } \\
\text { Urease } \\
\text { Carbolfuchsin } \\
\text { ELISA }\end{array}$ & $\begin{array}{l}45 \\
20 \\
26 \\
39\end{array}$ & $\begin{array}{l}90 \\
40 \\
52 \\
78\end{array}$ & $\begin{array}{l}79 \\
74 \\
73 \\
74\end{array}$ & $\begin{array}{l}79 \\
74 \\
73 \\
74\end{array}$ & $\begin{array}{l}100 \\
94 \\
92 \\
94\end{array}$ \\
\hline
\end{tabular}

A significant association was found between HP infection and GC ( $\mathrm{p}=$ $0.0007 ; \mathrm{OR}=13.8 ; 95 \% \mathrm{CI}=1.87-69.24)$ both intestinal $(\mathrm{n}=14,93 \%)$ and diffuse $(n=34,100 \%)$ ) types. The use of several methods for HP diagnosis allowed us to demonstrate that HP infection is strongly associated with an increased risk of distal GC in a developing country.

\section{A:13 GASTRIC CANCER, H. PYLORI (HP) INFECTION, SERUM ANTIBODIES TO CagA}

N. Figura ${ }^{1}$, C. Vindigni ${ }^{2}$, E. Pinto ${ }^{3}$, C. Gennari ${ }^{1}$, L. Presenti ${ }^{2}$, P. Tosi ${ }^{2}$ F. Roviello ${ }^{3} .{ }^{1}$ Institute of Internal Medicine, University of Siena, Siena, Italy; ${ }^{2}$ Institute of Pathology, University of Siena, Siena, Italy; ${ }^{3}$ Institute of Surgical Sciences, University of Siena, Siena, Italy

$H P$ infection is a major risk factor for gastric carcinogenicity. Strains expressing CagA $\left(\mathrm{CagA}^{+}\right)$are endowed with increased inflammatory potential which could contribute to mutagenic phenomena of gastric epithelial cells. We investigated the possible role of CagA ${ }^{+} H P$ infection in gastric cancer (GC) development. Ninety consecutive GC cases $(59$ males, mean age 68) were studied. Cancers were classified according to Lauren and staged according to UICC (1992). HP infection was investigated histologically and serologically by Western blotting (WB). The presence of serum IgG to CagA was investigated by WB. Ninety age-matched dyspeptic patients without GC were used as controls. The cancer site was cardial in $9 \%$ and non-cardial in $91 \%$ of cases. Histotypes were intestinal in $63 \%$, diffuse in $20 \%$, and unclassified/mixed in $17 \%$ of cases. Stages were $\mathrm{T}_{1}$ in $28 \%, \mathrm{~T}_{2}$ in $38 \%$ and $\mathrm{T}_{3}-\mathrm{T}_{4}$ in $34 \%$ of cases. Eight-eight GC patients $(97.7 \%)$ were $H P$ positive, vs. $72.3 \%$ of controls $(P<0.000$, Yates corrected test); $78 \mathrm{HP}^{+}$patients (88.6\%) had anti-CagA serum IgG, vs. $66.6 \%$ of $H P^{+}$controls $(P=0.0008)$. CagA seropositivity was found in $93 \%, 72 \%$ and $93 \%$ of intestinal, diffuse and unclassified or mixed type cases, respectively $(P=0.031$, Fisher exact test, intestinal type $v s$. diffuse type), and in $92 \%, 88 \%$ and $87 \%$ of $T_{1}, T_{2}$, and $T_{3--4}$ stage cases, respectively (non-significant). HP infection is strongly associated with GC development. CagA or factors expressed by $\mathrm{CagA}^{+}$strains could have a role in GC development, especially of the intestinal histotype.

\section{A:14 DIFFERENT EXPRESSION OF H. PYLORI-GASTRITIS IN RELATIVES OF GASTRIC CARCINOMA PATIENTS}

A. Meining, M. Stolte. Dept. of Medicine II, Klinikum Grosshadern, Univ. of Munich; Dept. of Pathology, Klinikum Bayreuth, Germany

Introduction: Infection with $H$. pylori is associated with an increased risk of gastric carcinoma (GC). However, it has also been reported that there may be a family risk for developing GC as well. 
Aim: To investigate whether $H$. pylori-gastritis differs in relatives of GC patients compared with sex- and age-matched controls.

Methods: 223 patients (mean age: 52.61 years, male: $\mathrm{n}=67$, female: $\mathrm{n}=$ 156), all infected with $H$. pylori, and having first or second degree relatives suffering on GC, were sex- and age-matched with 223 patients having merely $\boldsymbol{H}$. pylori-gastritis not associated with a known family history of GC. From each patient, 2 antrum and 2 corpus biopsy specimens were obtained and histologically investigated according to the Sydney System (score ranging from 0 to 4 ).

Results: Gastritis parameters in antrum and corpus:

\begin{tabular}{|c|c|c|c|c|}
\hline & \multicolumn{2}{|l|}{ Antrum } & \multicolumn{2}{|l|}{ Corpus } \\
\hline & GC-relat. & Controls & GC-relat. & Controls \\
\hline $\begin{array}{l}\text { Grade" }^{*} \\
\text { Activity" } \\
\text { Int. met. }\end{array}$ & $\begin{array}{l}3 / 3.17 * * * \\
3 / 2.92 \\
28.0 \% * * *\end{array}$ & $\begin{array}{l}2 / 2.24 \\
3 / 3.01 \\
12.6 \% \\
\end{array}$ & $\begin{array}{l}3 / 2.65^{* * *} \\
2 / 2.26 * * * \\
7.7 \% *\end{array}$ & $\begin{array}{l}1 / 1.52 \\
1 / 1.40 \\
3.2 \% \\
\end{array}$ \\
\hline
\end{tabular}

"median/mean, ${ }^{8}$ percentage, ${ }^{*} \mathrm{p}<0.05,{ }^{* * *} \mathrm{p}<0.0001$ ( $\chi^{2}$-Mann-Whitney-test)

Conclusion: The extend of $H$. pylori-gastritis in GC-relatives is significantly greater than in controls. Hence, there may be certain hereditary factors influencing $H$. pylori-gastritis, and thereby the risk of GC.

\section{A:15 CLINICAL AND ECONOMIC EFFECTS OF H. PYLORI SCREENING TO PREVENT GASTRIC CANCER}

A.M. Fendrick, M.E. Chernew, R.A. Hirth, J.M. Scheiman, B.S. Bloom ${ }^{1}$. University of Michigan, Ann Arbor, Michigan; ${ }^{1}$ University of Pennsylvania, Philadelphia, Pennsylvania, USA

Helicobacter pylori $(H p)$ infection has been identified as a risk factor for certain types of gastric cancer. The extent to which successful $H p$ eradication decreases gastric cancer risk remains unknown. The availability of non-invasive testing for $H p$ and effective $H p$ eradication therapy necessitates an evaluation of the potential clinical and economic effects of screening asymptomatic individuals for $\mathrm{Hp}$ in an attempt to prevent gastric cancer. Thus, we compared the potential clinical and cost consequences of 2 available $H p$ screening strategies to no screening at varying levels gastric cancer risk reduction after $H p$ eradication.

A Markov simulation estimated the impact of $\mathrm{Hp}$ eradication on the incidence of gastric cancer in several demographic cohorts. Three strategies were evaluated: 1) $H p$ serology, treat positives with eradication therapy, no further testing; 2) $\mathrm{Hp}$ serology, treat positives with eradication therapy, urea breath test (UBT) to confirm eradication, retreat positives; and 3) No screening or treatment. In the base case, gastric cancer risk after $H p$ eradication was assumed to be similar to those without $H p$ infection. Additional scenarios with less optimistic assumptions regarding cancer risk reduction were evaluated. $H p$ reinfection and antibiotic related adverse events were incorporated into the model. Individuals remained in the simulation until they died of either gastric cancer or of other causes. The model estimated the following outcomes for a cohort of asymptomatic 40 year old white males:

\begin{tabular}{llcl}
\hline Strategy & $\begin{array}{l}\text { Cost per patient } \\
\text { screened }\end{array}$ & Cancer/1,000 & $\begin{array}{l}\text { Cost per cancer } \\
\text { prevented }\end{array}$ \\
\hline 1) $H p$ serology & $\$ 117.75$ & 9.9 & $\$ 39,250$ \\
2) Hp serology, UBT & $\$ 220.06$ & 9.4 & $\$ 62,874$ \\
3) No screening & & 12.9 & \\
\hline
\end{tabular}

If $H p$ eradication reduced gastric cancer risk to that of those without infection, $\mathrm{Hp}$ serology alone reduced the cancer rate by $30 \%$ compared to no screening. Adding UBT to confirm eradication was more effective, but necessitated $\$ 206,000$ in incremental costs to prevent an additional cancer. The cost-effectiveness of $H p$ screening varied substantially as the level of cancer risk reduction was varied. However, sensitivity analysis revealed that even at moderate rates of risk reduction $(<50 \%), H p$ screening was worthwhile on both clinical and economic grounds. These findings suggest that population-based $H p$ screening has the potential to produce important health benefits at a reasonable cost. Controlled studies are necessary to quantify the clinical benefits resulting from $\mathrm{Hp}$ eradication and identify those demographic cohorts most likely to benefit from $\mathrm{Hp}$ screening.

\section{A:16 UPREGULATION OF EGF-RELATED GROWTH FACTOR MRNA EXPRESSION BY HELICOBACTER PYLORI IN GASTRIC MUCOSAL CELLS IN VITRO}

M. Romano, V. Ricci, P. Sommi, S. Caliendo, P. Ciamarra, T.L. Cover ${ }^{1}$, M.J. Blaser ', R.J. Coffey ${ }^{2}$. Gastroenterologia, II Univ, Napoli, Italy; ${ }^{1}$ Infectious Diseases; ${ }^{2}$ Gastroenterology, Vanderbilt University, Nashville, USA

Helicobacter pylori (HP) infection is associated with development of gastric adenocarcinoma in humans. The expression of EGF-related growth factors, such as transforming growth factor alpha (TGF alpha), amphiregulin (AR) and heparin-binding EGF-like growth factor (HB-EGF) is increased in gastrointestinal malignancies in humans. Aim: 1) to evaluate whether HP alters TGF alpha, AR, and HB-EGF mRNA expression in gastric mucosal cells in vitro and 2) to assess the role of the vacuolating cytotoxin (Tox) VacA and of the cytotoxin associated antigen CagA in any such effect. Methods: Cell culture: MKN 28 gastric mucous cells; mRNA Expression: assessed by northern blot. Studies: cells were incubated for 6 and $16 \mathrm{~h}$ with uninoculated broth filtrate (control), with broth culture filtrates (BCFs) or with bacterial suspensions (BSs) from Tox $+/ \mathrm{CagA}+\mathrm{HP}$ or its isogenic mutants lacking VacA or CagA or both. Results: 1) incubation with HP BCFs or with BSs did not affect TGF alpha expression but resulted in a 5-fold increase in AR mRNA expression and in a 10-fold increase in HB-EGF mRNA expression; 2) this effect was independent of the production of VacA or CagA or ammonia and was specifically related to HP since it was not observed with $E$. coli BCF or BS. Conclusions: 1) HP upregulates AR and HB-EGF, but not TGF alpha, mRNA expression in cultured gastric mucosal cells; 2) this effect does not depend on the production of either the vacuolating cytotoxin VacA or the cytotoxin associated antigen CagA nor is it related to ammonia production; 3 ) we speculate that the enhanced synthesis of EGF-related peptides may contribute to gastric carcinogenesis associated with HP infection.

\section{A:17 LACK OF REVERSIBILITY OF EPITHELIAL PROLIFERATIVE CHANGES AFTER HELICOBACTER PYLORI (HP) ERADICATION IN AREAS OF INTESTINAL METAPLASIA (IM)}

E. Ierardi, T. Balzano, A. Traversa, M. Principi, C. Sgarro, S. Passaro, A. Francavilla. Dept of Gastroenterology, University of Bari, Italy

Alterations of gastric epithelium proliferation have been described in HP infection. Previously, we reported a progressive increase of proliferating cells with the progression of mucosal lesions. Here, we report the effect of eradication on bacterium-induced proliferative changes and the relationship with ras p21 oncoprotein, which is involved in early events of gastric carcinogenesis.

The study was performed, before and 6 months after therapy, in 5 groups of 10 patients showing the progressive stages of HP damage (N: normality; HG: histological gastritis; EHG: histological gastritis with endoscopic chronic erosions; CIM: complete intestinal metaplasia; IIM: incomplete intestinal metaplasia). Gastritis was assessed by H-E, HP by Gram and specific IgG serum levels, IM by Alcian-PAS and Alcian-HID. Epithelial regeneration was evaluated by proliferating cell nuclear antigen labeling index (PCNA LI) using PC10 monoclonal antibody immunohistostain. Immunohistostain was also employed for ras p21 detection. ANOVA and Student-Neuman-Keuls tests were applied for statistic analysis of PCNA LI in all groups before and after therapy.

After HP eradication, we observed:

$-\mathrm{HP}$ and active inflammation disappearance

- unchanged extension and type of intestinal metaplasia

- normalization of PCNA LI in HG and EHG

- unchanged PCNA LI in CIM and IIM

Moreover, ras p21 membrane expression was observed in all patients with CIM and IIM. In 3 patients with IIM, the protein was additionally expressed in the cytoplasm.

These results suggest that intestinal metaplasia is associated with an alteration of gastric epithelium proliferation control and represents a stage of gastric carcinogenesis in which initiation and promotion have occurred. Nevertheless, the progression towards neoplasm requires further genetic changes. Local immune alterations, which occur in a proliferating tissue, may be relevant for this event.

\section{A:18 CYCLIN D1 EXPRESSION IN GASTRIC CARCINOGENESIS}

S.F. Moss, N. Arber, H. Hibshoosh, S. Wang, M.D. Gammon, I.B. Weinstein, P.R. Holt. St. Luke's-Roosevelt Hosp/Columbia Univ, New York, USA

Cyclin D1 (CD1) is an important cell cycle regulator, acting at the G1/S transition. Overexpression and amplification of CD1 occurs in several human cancers, suggesting that $\mathrm{CD} 1$ may function as an oncogene. The role of $\mathrm{CD} 1$ in gastric carcinogenesis is unknown.

Aim: To examine expression of CD1 by immunohistochemistry in normal mucosa, chronic $H$. pylori-gastritis and gastric carcinoma.

Methods: Retrospective study of archival tissue blocks by standard peroxidase histochemistry using polyclonal anti-CD1 primary antibody (UBI) Sections were considered positive if $>5 \%$ of epithelial cells stained. In non-cancer cases, sections were also stained with Mib-1 antibody to $\mathrm{Ki}-67$.

Results: In both $H$. pylori negative normal mucosa $(\mathrm{N}=23)$ and in $H$-pylori chronic gastritis $(\mathrm{N}=23)$, there was occasional perinuclear and cytoplasmic $\mathrm{CD} 1$ staining confined to mucous neck cells, but not elsewhere. 
There was no difference in immunointensity between normal and inflamed mucosa. Mib-1 labeling index was significantly higher in inflamed than normal mucosa (mean $8.0 \pm 6.4 \%$ vs $3.6 \pm 2.7 \%, p=0.02$ ) but $C D 1$ immunointensity was not correlated with Mib-1 labeling index.

In contrast, in gastric cancer, positive CD1 nuclear staining was evident in 15 of 32 cases $(47 \%)$, in both cardia $(8 / 18(44 \%)$ ), and non-cardia tumors $(7 / 14(50 \%)$ ); more commonly in intestinal (68\%) than in diffuse-type (13\%) tumors.

Conclusions: $\mathrm{CD} 1$ is overexpressed in around half of all gastric cancers, irrespective of site. Overexpression is not merely a reflection of hyperproliferation since CD1 was not overexpressed in hyperproliferative non-neoplastic mucosa. CD1 may function as an oncogene in gastric carcinogenesis, by perturbing cell cycle control.

\section{A:19 REGRESSION OF MURINE MUCOSA-ASSOCIATED LYMPHOID TISSUE (MALT) LYMPHOMA AFTER TRIPLE THERAPY}

A. Enno, J. O'Rourke, C.R. Howlett, A. Lee. The University of New South Wales, Sydney, Australia

Aim: In human studies there is evidence that low-grade B-cell gastric mucosa-associated lymphoid tissue (MALT) lymphomas respond to antigenic stimuli, with eradication of $H$. pylori by triple therapy resulting in tumour regression. In this study we investigated the effects of triple therapy in the $H$. felis MALT lymphoma model.

Method: Mice infected for 20 months with $H$. felis were treated with triple therapy (TT; bismuth subcitrate, tetracycline and metronidazole). Control animals consisted of age-matched $H$. felis infected, uninfected and uninfected triple therapy treated mice. Groups of mice were sacrificed 2, 3 and 4 months after triple therapy, i.e. 22,23 and 24 months after the initia infection. Sections of stomach were coded and examined for lymphoid cell proliferation and bacterial colonisation.

Results: To date, only the results for 22 and 23 months post-infection are available. The results for both time points are identical and are pooled in the following table:

\begin{tabular}{lll}
\hline 22 \& 23 months & Lymphoid follicles & MALT lymphoma \\
\hline Uninfected & $0 \%(0 / 30)$ & $0 \%(0 / 30)$ \\
Uninfected + TT & $0 \%(0 / 25)$ & $0 \%(0 / 25)$ \\
$H$. felis infected & $69 \%(11 / 16)$ & $88 \%(14 / 16)^{*}$ \\
$H$. felis infected + TT & $23 \%(7 / 30)$ & $33 \%(10 / 30)$ \\
\hline
\end{tabular}

${ }^{*} \mathrm{p}=0.001\left(\chi^{2}\right)$ cf. $H$. felis infected $+\mathrm{TT}$

Conclusion: The reduced incidence of MALT lymphoma after $H$. felis eradication indicates that the low-grade MALT lymphomas induced by $H$. felis remain dependent on antigenic stimulation. In human gastric MALT lymphomas a similar antigen dependence is also observed. This animal model provides an opportunity to study the mechanisms of induction of antigen-driven lymphomas and establish the point at which tumour proliferation is independent of antigen stimulation.

\section{A:20 MEASUREMENT OF DNA SINGLE STRAND BREAKS IN $H$. PYLORI ASSOCIATED GASTRITIS}

S.M. Everett, K. White, R. Calvert, C. Skinner, D. Miller, C.J. Schorah, A.T.R. Axon. Centre for Digestive Diseases, Leeds General Infirmary, Leeds, UK

Purpose Infection with $H$. pylori increases the risk of developing gastric carcinoma. To date, however, no study has linked this infection with DNA damage in the gastric mucosa. Single cell electrophoresis (The "Comet" assay) has been extensively used in vitro for measuring DNA single strand break (SSB's). The aim of this study was, therefore, to measure DNA SSB's in isolated gastric epithelial cells, and compare levels in patients with and without $H$. pylori infection.

Methods In patients undergoing endoscopy for dyspepsia, biopsies were taken for $H$. pylori histology, culture and urease test, and for the "Comet" assay. Cells are isolated from biopsies using pronase and collagenase. The technique then relies on the migration of DNA fragments in an electric field cells with DNA SSB's appear as a "comet" under fluorescent microscopy, and are counted as a percentage of the total.

Results 62 patients were included. Median age was 62.5 years. Two had DU, and 1 had GU. Histology revealed: $31 \mathrm{H}$. pylori gastritis, 11 normal, 11 reactive gastritis, and $9 H$. pylori negative chronic gastritis. The median comet counts were: $H$. pylori gastritis $19.2 \%$, normal mucosa $64.5 \%$, reactive gastritis $51.0 \%$, and $H$. pylori negative chronic gastritis $50.5 \%$.

Conclusions Surprisingly, fewer DNA SSB's were detected in gastric epithelial cells of patients with $H$. pylori infection when compared to normal mucosa ( $\mathrm{p}<0.0001$ ), whilst reactive gastritis and $H$. pylori negative chronic gastritis show intermediate levels. We believe this may be a consequence of altered rates of apoptosis or DNA repair in $H$. pylori infected mucosa.

\section{A:21 PRESENCE OF THE CagA GENE SUGGESTED NO SPECIFIC ASSOCIATION BETWEEN CagA-POSITIVE H. PYLORI} STRAINS AND GASTRIC CANCER

T. Mikami, T. Shimoyama, S. Fukuda, Y. Saito, A. Munakata. Hirosaki Univ. School of Medicine, Hirosaki, Japan

Purpose: Previous serological studies have shown the infection of $H$. pylori strains possessing cagA gene is associated with an increased risk of developing atrophic gastritis and gastric cancers. In this study, we investigated that whether the strains possess cagA more frequently in gastric cancer patients comparing with chronic gastritis patients using polymerase chain reaction.

Method: DNA extracted from a total of 72 isolates of $H$. pylori from human gastric biopsies were tested for the presence of the cagA gene. $H$. pylori were isolated from 35 early gastric cancer patients ( 25 were men, age ranged 43-83 years old) and 37 controls (14 were men, age ranged 35-86 years old) who have no previous history of gastric tumors and gastro-duodenal ulcers. PCR amplification was performed in duplicate using $0.1 \mathrm{mg}$ of prepared DNA. A 35 cycles of PCR including 40 seconds denaturation at $94^{\circ} \mathrm{C}$, 40 seconds annealing at $50^{\circ} \mathrm{C}$ and 60 seconds polymerization at $72^{\circ} \mathrm{C}$ were performed using a pair of primers, $5^{\prime}$-GATAACAGGCAAGCTTTTGAGG$3^{\prime}$ and $5^{\prime}$-CTGCAAAAGATTGTTTGCGAGA-3' as previously described.

Results: Proportions of cagA-positive strains were $100 \%$ in gastric cancer patients and 95\% (35 out of 37 strains) in controls. The difference was not statistically significant (Fisher's exact test). There was also no significant difference in sex and age matched 21 cancer and control pairs.

Conclusions: Present results suggested that there was no specific association between cagA-positive $H$. pylori strains and gastric cancer. However, frequent presence of cagA-positive strains might associate with progression of atrophic gastritis in Japanese patients.

\section{A:22 P 53, INTESTINAL METAPLASIA AND HELICOBACTER PYLORI}

M. Caselli ${ }^{1}$, G. Lanza ' , M. Gaudio ${ }^{2}$, L. Saragoni ${ }^{2}$, C.M. Chimenti ${ }^{1}$, P. Gaudenzi ${ }^{1}$, S. Sartori ${ }^{1}$, V. Alvisi ${ }^{1}$. ' ${ }^{1}$ School of Gastroenterology and Institute of Pathology, University of Ferrara, Italy; ${ }^{2}$ Institute of Pathology, Pierantoni Hospital of Forli', Italy

The p53 gene is a "guardian of the genome". Cells presenting p53 gene mutations are at high risk for malignant transformation and mutations in p 53 tumor suppressor gene represent the most frequent genetic alteration in human solid malignancies. High percentage of p53 mutations has recently also been detected in intestinal-type gastric carcinoma. Since H. pylori has been epidemiologically implicated in the pathogenesis of both gastric cancer and intestinal metaplasia, we investigated with immunohistochemical analysis, by using PAb 1801 monoclonal antibodies, the possible presence of nuclear p53 protein immunostaining in 22 patients presenting isolated intestinal metaplasia $(12 \mathrm{H}$. pylori-positive and $10 \mathrm{H}$. pylori-negative). Nuclear p53 protein immunostaining, graded from 1 to 4 in relation to the intensity of nuclear labelling, were detected in 10 of the $12 \mathrm{H}$. pylori-positive patients $(83.3 \%)$ and in 2 of the $10 \mathrm{H}$. pylori-negative patients $(20 \%)$, with an highly significant difference $(p<0.001)$. The great majority $(75 \%)$ of $\mathrm{p} 53$-positive areas of intestinal metaplasia had more than $30 \%$ reacting cells. These alterations, however, were only seen in the proliferative compartment of the glands, while they were virtually never recognized in superficial intestinal metaplasia. In addition to confirm that p53 mutations may represent an early event in stomach tumorigenesis, it seems that $\mathrm{p} 53$ alterations are closely related to $\mathrm{H}$. pylori infection. This may add new knowledge in the pathogenesis of gastric cancer. 